\title{
SUBVENCIONES PERNICIOSAS
}

\section{HARMFUL SUBSIDIES}

José Antonio Martínez Pons: Departamento de Química Analítica e Ingeniería Química. Universidad de Alcalá de Henares. Madrid (España) joseantonio.martines@uah.es

\section{CURRÍCULUM VITAE}

Licenciado en Ciencias Físicas (Geofísica) por la Universidad Complutense de Madrid (España) y en Ciencias Químicas (Química física) por la UNED (España). Doctor por la Universidad de Alcalá de Henares (España) en el año 2000. Profesor de la Universidad de Alcalá de Henares en el área de Química analítica e Ingeniería química.

\section{RESUMEN}

En España está muy de moda solicitar subvenciones, ya sea al estado, la autonomía, el municipio o el barrio. Hay casos en los que dichas subvenciones no tienen sentido, como en el de las ONG's. Una ONG subvencionada implica contradicción en los términos. Otro caso que se analiza en este artículo es el de determinadas actividades comerciales que se camuflan de culturales, como el cine, o las que se dan a los sindicatos.

\section{PALABRAS CLAVE}

Subvención - ONG - Cine - Sindicato 


\begin{abstract}
In Spain is very fashionable to apply for grants, whether state, autonomy, the municipality or neighborhood. There are cases in which such subsidies do not make sense, as in the NGO's. An NGO funded a contradiction in terms. Another case discussed in this paper is to certain commercial activities that camouflage of culture such as cinema, or given to the unions.
\end{abstract}

\title{
KEY WORDS
}

Grant - NGOs - Cinema - Union

\section{TEXTO}

Quizás sea consecuencia de los malos hábitos adquiridos durante los largos periodos de dictadura oficial u oficiosa padecidos en España a lo largo del pasado siglo XX. Quizás, profundizando un poco más, como consecuencia del subconsciente colectivo, católico, con una fe profunda en la Providencia Divina, desacralizado en forma de providencia gubernativa, si algo caracteriza a este país otrora llamado España, es el culto a la subvención.

En efecto, cuando se funda, desde una gran fundación hasta el más modesto club de amigos de la boina, lo primero, incluso antes de firmarse el acta constitutiva y de pasar por el registro, es leerse el montón de boletines oficiales del estado, autonomía, municipio o barrio a la búsqueda de la pertinente subvención. Naturalmente, una vez localizada la mentada subvención, no se olvide que estamos en España, habrá 
que buscar al primo del tío del amigo que pueda inclinar el dedo del omnipotente de turno hacia el proyecto objeto de tal sinecura.

Hay casos en que las cosas se producen al revés, es decir, primero es la subvención y luego el recipiendario, en forma de esposa/o, coima/o, hijo/a, sobrino/a, cuñado/a, hombre/mujer de paja/o cuando no el propio discrecionador de la subvención. (Más o menos lo mismo que ocurre con ciertos premios artísticos, "pero esto, mi señora, ya es otro cantar", como dice la zarzuela, Luisa Fernanda por más señas; tal vez un día escriba algo sobre el tema).

Una vez conseguida la subvención, cruzando los dedos para que ningún periodista entrometido introduzca las narices de por medio, a vivir que son dos días. En el mejor de los casos, se llenan unos folios justificando a dónde han ido a parar los dineros -nadie se va a preocupar de hacer el más mínimo seguimiento-, se presentan en el registro correspondiente, se adjuntan, si son precisas, algunas facturas -mientras haya papeles de por medio nadie levantará la liebre-. A veces no hace falta ni eso y hale, a seguir buscando una nueva subvención que permita seguir medrando.

Aquí se pide subvención pública para todo y se subvenciona casi todo. Naturalmente, si llueve demasiado, los agricultores pedirán subvención, si no llueve, también. Hasta los ganaderos de bravo pidieron subvención cuando, por lo de las vacas locas, no podían vender los canales. Sin embargo, que yo sepa, no se ha constituido, de momento, ninguna asociación de gentes que han perdido en la bolsa por el 11-S o el 11-M o que llevan 20 años sin que les toque ni un reintegro en la lotería, pero todo es proponérselo.

En resumen, se trata de envolver bien el engendro y encontrar, como ya se dijo, el padrino adecuado. Indudablemente, se tienen muchas más probabilidades de lograr el ansiado socorro si el proyecto se "inscribe" en las coordenadas político sociales 
imperantes y se arropa con una adecuada literatura, en la cual, por supuesto, se evite el lenguaje sexista, aunque con ello se asesine el castellano, catalán, gallego, panocho o castúo (no mallorquín de Binissalem o de la plaça Pescateria, antes Rastrillo, no vale, debe ser català estándar), y se utilicen los topónimos según la nueva terminología y se repita en cantidad suficiente, democrático, democracia, cultura popular, solidaridad etc.

La razón de la subvención es lo de menos, si hasta se ha subvencionado un estudio sobre la lenteja libia, lo que importa es quien lo pide y quien lo concede. Valga de ejemplo una de las últimas ofertas de subvención. Me entero de que se ha dictado una orden ministerial en la que abre una línea de subvenciones especiales «a las asociaciones y agrupaciones de particulares que trabajan por la recuperación de la memoria histórica». Según la disposición, podrán optar a subvenciones aquellas asociaciones, fundaciones y organizaciones constituidas antes del 10 de septiembre de 2004 para realizar trabajos de «investigación, exhumación e identificación de desaparecidos violentamente durante la guerra civil o durante la represión política posterior y cuyo paradero se ignore». ¿No hay mejor forma de gastar el dinero de todos?

Por cierto, quizás se pueda pensar que sólo la izquierda es pródiga en subvenciones, pues no, tanto o más lo es la derecha, aunque para ésta el envoltorio debe ser todavía más tópicamente pro proletario, no vayan a pensar que se deniega la subvención atendiendo no a la estupidez del proyecto sino a que es "de izquierdas".

Entre las muchas subvenciones, hay algunas que no entiendo en absoluto. Me refiero a las que se conceden a las Organizaciones No Gubernamentales (vulgo ONG). Me parece que una ONG subvencionada implica contradicción en los términos. Entiendo que si una ONG pretende ser eso, ONG, lo primero que debe hacer es buscarse sus fondos sin contar con el gran pagano. Si la tal ONG no es capaz de convencer al 
ciudadano de a pié que la ayude, es que no merece ser ayudada. (Ya se sabe, "Quien paga manda").

Aquí corro un tupido velo sobre qué porcentaje de cada euro recaudado, donado o subvencionado llega a aplicarse a su destino natural y cuantos se invierten en sueldos, dietas, viáticos, regalos, obsequios y comilonas. Debo decir que, por razones que no vienen a cuento, conozco desde dentro a alguna de las más prestigiosas. Oído por mis oídos pecadores en la sede central internacional de la mentada: "Hay quien se cree que esto es una agencia de viajes" (lo traduzco para no dar más pistas). Si alguien tiene curiosidad, hace unos años, bastantes, se publicó un librito que ponía el dedo en la llaga, se titulaba "Los protectores".

Otro tipo de subvenciones que no entiendo son aquellas que se destinan a lo que son, lisa y llanamente, actividades comerciales, por mucho que se las camufle de "culturales"; la primera el cine. ¿Por qué tengo que pagar con mis impuestos lo que no estoy dispuesto a pagar pasando por taquilla? O la recíproca: ¿Por qué tengo que pagar en taquilla lo que ya he pagado con mis impuestos? Lo más triste es que muchas películas se subvencionan, y no es que no hagan un real de taquilla porque aburren hasta a las tortugas, sino que ni siquiera se estrenan. Encima no parece que el nivel de vida de los mendicantes del cine corresponda al de los hijos auténticos del Poverello, sino más bien al de niños de papá. En la misma categoría englobo los "pases de modelos" o "pasarelas" que, además de ser un acto promocional de una industria privada, (no creo que los diseñadores entreguen un céntimo de lo que venden, si venden algo pues ¿alguna mujer en su sano juicio puede ponerse, para ir por la calle, semejantes adefesios?), son una promoción de la anorexia.

Igualmente grave, aunque no se trate propiamente de una subvención, me parece el dinero destinado a mantener lujos ajenos, como el Teatro Real, mantenido con dinero de todos pero que sólo unos pocos, los que pueden pagar la entrada sin subvención, 
gozan de él. A mí me parecería muy bien un teatro de ópera con buenos profesionales, no con divos ni con escenógrafos "pirados", al que se pudiera acceder a un precio asequible. Hace unos días busqué entradas en Internet. Había a... $200 €$ o de baja (eufemismo para no decir nula) visibilidad. Además me entero que grandes empresas obsequian con localidades a sus clientes distinguidos, es decir, mis impuestos sirven para que ciertas empresas hagan buenos regalos, encima a personas que no los necesitan o no son capaces de apreciarlos. Algunos gorrones, sí van, se salen al acabar el primer acto, "ya les han visto". ¿Genial, no?

Y no me digan que esto es cultura. Que yo sepa no se subvenciona a los pintores que no venden, a los escritores que no publican o los entrenadores de futbolistas que no descubren ningún cazatalentos.

Otro tipo de subvención que me solivianta es la que se da a los sindicatos. Vamos a ver, según la estadística, no llega al $10 \%$ el número de trabajadores sindicados. En las elecciones sindicales, no pasa del 50 \% el número de votantes. Me parece que está claro que la mayoría de trabajadores pasan olímpicamente de sus autotitulados "representantes". Comprendo que después de 40 años de sindicatos verticales y obligatorios, había que crear una conciencia sindical, pero han pasado 30 años y en estos 30 años las cosas siguen igual ¿Para qué se van a molestar los sindicalistas en captar afiliados y convencerles de que, si quieren un sindicato, deben manutenerlo, si es más cómodo ordeñar la vaca?

También en este tema sé de lo que hablo, he pertenecido, "por hacer un favor", varios años a la junta sindical de personal docente. Más de una vez pensé en grabar un video de la sesión y mandarlo a los centros. Si después de aquel espectáculo, alguien votaba en las elecciones merecía que le dieran musculillo. Pero ahí están legiones de liberados, gastando pólvora del rey, incluso, en el campo que yo conozco, doblando al Ministerio organizando cursos subvencionados. 
Respecto a estos últimos, no tengo nada que objetar si los organizan con sus propios fondos, ni siquiera me opondré a que se les dé valoración, digamos, académica, siempre mediando la correspondiente inspección (conste que he visto rechazar, en un concurso de traslado, un curso universitario, de la UNED, pagado por el interesado, para cuya superación hubo de hacer dos trabajos monográficos y pasar un examen, porque "no figuraban las horas", y, sin embargo, valorar un curso de 30 horas de Power Point. Lo que se enseñó yo, que no soy ningún genio, lo aprendí en veinte minutos y me sobraron diez).

Insisto, si los trabajadores españoles no se dan cuenta de que, si quieren unos sindicatos de verdad, estos sindicatos deben empezar por ser independientes del gobierno y la primera independencia empieza por la autonomía económica, no merecen tenerlos. Por cierto, que a más de un conspicuo sindicalista, que vivía muy bien del cuento, he escuchado despotricar contra las subvenciones a la Iglesia Católica, a la cual está "afiliado" más del 80 \% de la población y cuyas obras sociales y culturales están a años luz de las de los sindicatos, los peliculeros y los redentores del género humano. Basta con echar mano a una calculadora y sacar cuentas de lo que constaría, en este momento, suplir a las monjas que trabajan en docenas de centros asistenciales, pagar alquiler de locales, etc.

Otro líder sindical se descolgó, eran los años de la transición, con la flor de la necesidad de obligar a todos los trabajadores a sindicarse.

Repito, quizás en su momento se podrían entender, hasta que el pueblo tomara conciencia de que si quería unos sindicatos debía pagarlos, unas ayudas, pero lo que se ha conseguido es todo lo contrario: tenemos unos sindicatos alimentando una burocracia descomunal, desproporcionada, pagada por todos. 
En fin, sé que con ello mi pensamiento es neoliberal, me da igual, pero mi opinión es que subvenciones, las menos y siempre dadas con estricto control y responsabilidad, incluso penal, de quien las da y de quien las recibe, más de quien las da. Naturalmente, las subvenciones siempre destinadas al real bien común, no al bien privado de unos pocos, ni a pagar con dinero público favores privados como en mi humilde opinión ocurre ahora.

PS.: No he comentado ciertas denegaciones de subvenciones, de todos conocidas, ni su concesión a familiares de criminales porque, sólo a su mención mi cerebro se cortocircuita. Es gracioso que quienes reniegan de España no le hagan ascos al dinero de España. Tampoco he comentado las subvenciones a la investigación científica a través de los "idearios" de I+D, porque será motivo de algún comentario futuro en esta misma revista. 